\title{
Estradiol promotes the development of a fibrotic phenotype and is increased in the serum of patients with systemic sclerosis
}

Keiko Aida-Yasuoka', Christine Peoples ${ }^{2}$, Hidekata Yasuoka ${ }^{1}$, Pamela Hershberger ${ }^{3}$, Katelynn Thiel ${ }^{1}$, Jane A Cauley ${ }^{4}$, Thomas A Medsger $\mathrm{Jr}^{2}$ and Carol A Feghali-Bostwick ${ }^{*}$

\begin{abstract}
Introduction: Systemic sclerosis (SSC) is more prevalent in women. Our goal is to determine the effects of $17 \beta$ estradiol (E2) on the development of fibrosis and to compare circulating levels of estrogens in SSc patients and healthy controls.
\end{abstract}

Methods: Using primary human dermal fibroblasts, we evaluated the effect of E2 on fibronectin (FN) expression with and without the estrogen receptor (ER) antagonist ICI 182,780, inhibitors of signaling, propyl-pyrazole-triol, an $E R \alpha$ specific ligand, and genistein, an ERß selective ligand, to identify the signaling pathways mediating E2's effect. We confirmed the fibrotic effect of E2 in human skin using an ex vivo organ culture model. Lastly, we measured levels of E2 and estrone in serum samples from SSc patients with diffuse cutaneous involvement and healthy controls using mass spectrometry.

Results: E2 increased expression of FN in dermal fibroblasts. ICI 182,780, inositol-1,4,5-triphosphate inhibitor, and p38 mitogen-activated protein kinase inhibitor blocked the effects of E2 on FN. Propyl-pyrazole-triol, but not genistein, significantly increased FN expression. Ex vivo, E2 induced fibrosis of human skin. The effects of E2 were abrogated by ICI 182,780. Circulating levels of E2 and estrone were significantly increased in sera of patients with diffuse cutaneous SSC.

Conclusion: Our findings implicate estrogens in the fibrotic process and may explain the preponderance of SSc in women. ICI 182,780 or other ER signaling antagonists may be effective agents for the treatment of fibrosis.

\section{Introduction}

Systemic sclerosis (SSc) is a connective tissue disease characterized by fibrosis of the skin and internal organs due to fibroblast proliferation and excessive production of extracellular matrix (ECM) [1]. The mechanism(s) resulting in fibrosis in SSc are still under investigation. There are currently no effective treatments to prevent or halt the progression of fibrosis in SSc or other fibrosing diseases [2]. SSc has a worldwide distribution and is more frequent in women than men [3]. The female:male ratio is approximately $3: 1$, but this ratio increases to 10:1 during the child-bearing years [1]. Female sex

\footnotetext{
* Correspondence: feghalica@upmc.edu

'Division of Pulmonary, Allergy, and Critical Care Medicine, Department of Medicine, University of Pittsburgh School of Medicine, 3459 Fifth Avenue, 628 NW MUH, Pittsburgh, PA 14213, USA

Full list of author information is available at the end of the article
}

hormones such as estrogens may thus contribute to disease pathogenesis.

There are three main estrogens: estradiol, estrone, and estriol. Estradiol and estrone are the estrogens found in nonpregnant women, while estriol is the estrogen of pregnancy. Estrogens, especially $17 \beta$-estradiol (E2), play an important role in many normal physiological processes in mammals such as reproduction, cardiovascular health, bone integrity, cognition, and behavior [3]. Given this widespread role for E2 in human physiology, E2 is also implicated in the development or progression of numerous diseases - including various types of cancer (breast, ovarian, colorectal, prostatic, endometrial), osteoporosis, neurodegenerative diseases, cardiovascular disease, insulin resistance, endometriosis, and obesity [4-8]. In many of these disorders, estrogen mediates its effects

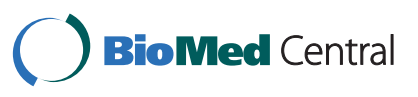


through the estrogen receptors (ERs), which serve as the targets for many therapeutic interventions.

The clinical effects of hormone replacement therapy (HRT) and tamoxifen, a selective ER modulator, have been evaluated in SSc patients $[9,10]$. HRT was suggested to exert protective effects against the development of isolated pulmonary hypertension in patients with SSc and limited cutaneous involvement [9], while tamoxifen did not improve SSc symptoms [10]. We examined the effects of E2 on fibronectin (FN), an important component of the ECM, and on the development of dermal fibrosis in human skin in organ culture. We also compared estrogen levels in sera of patients with diffuse cutaneous SSc and healthy controls.

\section{Materials and methods Source of fibroblasts}

Skin-punch biopsies were obtained with informed consent under an Institutional Review Board-approved protocol at the University of Pittsburgh from the clinically affected and unaffected skin of six patients with SSc and five healthy twins from an existing twin cohort $[11,12]$. Healthy twins were used as controls since they share the genetic background as the SSc patients. All SSc patients had diffuse skin thickening and met the American College of Rheumatology preliminary criteria for classification as SSc [1].

Biopsies were performed on the leading edge of dermal thickening and clinically normal skin. The skin samples were minced, placed in $60 \mathrm{~mm}$ tissue culture dishes, and cultured at $37^{\circ} \mathrm{C}$ in a humidified atmosphere in DMEM (Cellgro, Herndon, VA, USA) supplemented with 10\% fetal bovine serum (Sigma-Aldrich, St Louis, MO, USA), 100 $\mathrm{IU} / \mathrm{ml}$ penicillin, and $100 \mu \mathrm{g} / \mathrm{ml}$ streptomycin (Invitrogen, Carlsbad, CA, USA).

\section{Serum samples}

Serum was obtained from postmenopausal patients with diffuse cutaneous SSc $(n=68)$ and from age-matched and sex-matched healthy controls $(n=35)$. Both groups had no exposure to HRT. The average age of the SSc patients was $67.6 \pm 5.2$ years and that of controls $66 \pm 0.84$ years (not significant). Patients with SSc had disease duration $<3$ years, with onset defined as the time of the first symptom attributable to SSc.

Treatment of cells with $17 \beta$-estradiol, ER ligands and $17 \beta$ estradiol signaling inhibitors

Skin fibroblasts $\left(2 \times 10^{5}\right.$ cells per well $)$ were seeded in 35 $\mathrm{mm}$ cell culture dishes in DMEM/10\% fetal bovine serum. The following day, the medium was replaced with phenol-red free DMEM (Cellgro) without serum for 24 hours to deprive the cells of estrogen. Fresh phenol red-free DMEM plus 10\% charcoal-stripped fetal bovine serum (Hyclone, Logan, UT, USA) was added with one of the following: ethanol as vehicle control $(0.1 \%)$ or E2 (10 nM; Sigma-Aldrich) for 24 hours (for RNA extraction) or 48 hours (for protein extraction). Transforming growth factor beta $(10 \mathrm{ng} / \mathrm{ml}$; R\&D Systems, Minneapolis, MN, USA) was used as a positive control. ICI 182,780 (100 nM; Tocris, Ballwin, MO, USA), a pure ER antagonist, and signaling inhibitors (MEK inhibitor U0126, inositol-1,4,5-triphosphate (PI3K) inhibitor LY294002, and p38 mitogen-activated protein kinase (MAPK) inhibitor SB202190, $10 \mu \mathrm{M}$ each; Cell Signaling Technology, Beverly, MA, USA) were added where indicated. To determine the role of ER $\alpha$ and ER $\beta$ on FN individually, cells were cultured with propyl-pyrazole-triol (PPT), an ER $\alpha$ specific ligand (100 nM; Tocris) [13], and genistein, an ER $\beta$ selective ligand (100 nM; Sigma-Aldrich), under similar conditions to those used for E2 treatment.

\section{Extracellular matrix extraction}

ECM was extracted as we have described previously [14]. Briefly, cells were rinsed with PBS and incubated with $8 \mathrm{M}$ urea in PBS for 20 minutes. Cells were aspirated and the ECM was rinsed three times with PBS. ECM from an equal number of cells was scraped in 100 $\mu$ l sample buffer (20 mM dithiothreitol, 6\% SDS, $0.25 \mathrm{M}$ Tris, pH 6.8, 10\% glycerol, $10 \mathrm{mM} \mathrm{NaF}$, and bromophenyl blue) and analyzed by western blot. Equal volumes of ECM were loaded in each lane.

\section{RNA isolation and RT-PCR}

Skin fibroblasts in early passage (passages 3 and 4 ) were harvested and RNA was extracted using TRIzol (Invitrogen). mRNA was reverse transcribed using Superscript II (Invitrogen) following the manufacturer's recommendations. The cDNA generated was used as a template for amplification by PCR with primers specific for FN, 5'ACCGTGTGGGTACAGGTG-3' and 5'-GTCACAGAGG CTACTAT-3', and $\beta$-actin, 5'-ATGTTTGAGACCTTCA ACAC-3' and 5'-CACGTCACACTTCATGATGG-3'. PCR amplification was performed in a $50 \mu$ reaction containing Taq DNA polymerase (Invitrogen), 10× PCR buffer (750 $\mathrm{mM}$ Tris- $\mathrm{HCl}, \mathrm{pH} 8.8,200 \mathrm{mM}\left(\mathrm{NH}_{4}\right)_{2} \mathrm{SO}_{4}$ and $0.1 \%$ Tween 20), $1.5 \mathrm{mM} \mathrm{MgSO}_{4}$, and $1 \mathrm{mM}$ of each deoxynucleotide triphosphate in a Peltier Thermal Cycler-200 (MJ Research, Waltham, MA, USA).

Conditions were an initial denaturation at $95^{\circ} \mathrm{C}$ for 4 minutes, followed by 35 cycles of $94^{\circ} \mathrm{C}$ for 45 seconds, $55^{\circ}$ $\mathrm{C}$ for 30 seconds, and $68^{\circ} \mathrm{C}$ for 2 minutes. Final extension was at $68^{\circ} \mathrm{C}$ for 5 minutes. Then $20 \mu \mathrm{l}$ each reaction was electrophoresed on a $1 \%$ agarose gel in $1 \times$ Tris/acetate/ ethylenediamine tetraacetic acid buffer and products were visualized following staining with ethidium bromide. The molecular weights of the PCR products were: FN $513 \mathrm{bp}$ and $\beta$-actin $494 \mathrm{bp}$. 


\section{Protein extraction and western blot}

Cells were grown to confluency in $35 \mathrm{~mm}$ culture dishes. Cells were rinsed with $1 \times$ PBS and scraped in sample buffer (20 mM dithiothreitol, 6\% SDS, $0.25 \mathrm{M}$ Tris, $\mathrm{pH}$ 6.8, $10 \%$ glycerol, $10 \mathrm{mM} \mathrm{NaF}$, and bromophenyl blue). Samples were separated by electrophoresis on $8 \%$ SDS-polacrylamide gels and transferred to nitrocellulose membranes. Membranes were blocked with $5 \%$ nonfat milk in $1 \times$ TBSTween 20 (0.2 M Tris, 0.14 M NaCl, 0.1\% Tween 20), followed by incubation with mouse monoclonal antihuman EDA-FN antibody, rabbit polyclonal anti-human FN antibody, rabbit polyclonal anti-ER $\alpha$ antibody, rabbit polyclonal anti-ER $\beta$ antibody (Santa Cruz Biotechnology, Santa Cruz, CA, USA), mouse monoclonal anti-human vitronectin, mouse monoclonal anti- $\beta$-actin (SigmaAldrich), or mouse monoclonal anti-GAPDH (Ambion, Austin, TX, USA) in 1× TBS-Tween 20. Membranes were then incubated with horseradish peroxide-conjugated donkey anti-rabbit IgG (Amersham, Piscataway, NJ, USA) or donkey anti-mouse IgG (Amersham). Immunoreactive proteins were detected by chemiluminescence (PerkinElmer Life Sciences, Boston, MA, USA), followed by autoradiography.

\section{Treatment of human skin ex vivo}

Human abdominal skin was obtained from cosmetic plastic surgery. All tissues were obtained according to the guidelines of the University of Pittsburgh and under a protocol approved by the Institutional Review Board of the University of Pittsburgh. As described previously [15], subcutaneous fat tissue was removed uniformly and samples composed of complete epidermal and dermal strata were cut into $1.5 \mathrm{~cm} \times 1.5 \mathrm{~cm}$ sections. Skin was maintained in organ culture in the presence of the indicated factors, E2 (10 nM), ICI 182,780 (100 nM), PPT (100 nM), and genistein (100 nM). Skin was harvested, fixed in $10 \%$ formalin, and embedded in paraffin.

\section{Measurement of skin dermal and collagen bundle thickness}

Dermal and collagen bundle thickness were measured in skin sections stained with $\mathrm{H}$ \& E. Dermal thickness was defined as the distance from the granular layer to the junction between the dermis and subcutaneous fat. Images were taken on a Nikon Eclipse 800 microscope (Nikon Instruments, Inc., Huntley, IL, USA) using identical camera settings, and ImageJ (National Institutes of Health, Bethesda, MD, USA) was used to measure thickness. Thickness was measured in five random fields in each sample.

\section{Immunohistochemistry}

Sections $(6 \mu \mathrm{m})$ of paraffin-embedded skin tissues were de-paraffinized, endogenous peroxidase was quenched using $10 \% \mathrm{H}_{2} \mathrm{O}_{2}$, and endogenous biotin was blocked using the biotin blocking kit (Dakocytomation, Carpinteria, CA, USA). The sections were blocked with 5\% serum and incubated with anti-FN antibody followed by secondary antibody. Bound secondary antibody was detected using the aminoethyl carbazole Red kit (Invitrogen, Carlsbad, CA, USA). A light hematoxylin counterstain was used to identify nuclei. Images were taken on a Nikon Eclipse 800 microscope.

\section{Measurement of $17 \beta$-estradiol and estrone in serum}

Serum levels of E2 and estrone were measured using liquid chromatography-tandem mass spectrometry in the Small Biomolecule Core Facility in the School of Pharmacy at the University of Pittsburgh. The liquid chromatography-tandem mass spectrometry method employs liquid-liquid extraction, derivatization, and detection with a triple quad mass spectrometer using $0.5 \mathrm{ml}$ serum.

\section{Statistical analysis}

For the in vitro and ex vivo data, statistical comparisons were performed using the Mann-Whitney U test. For the comparison of serum levels of E2 and estrone, two separate sets of analyses were performed: case versus control comparisons of estrone and E2; and case-only comparisons of clinical manifestations based on high, intermediate, and low estrone or E2. For these comparisons, the Wilcoxon rank-sum test, the chi-square test of proportions, and Fisher's exact test were used where appropriate.

\section{Results}

\section{Effect of $17 \beta$-estradiol on fibronectin mRNA and protein} levels

The effect of E2 on FN expression was examined using RT-PCR and western blot analysis. In untreated samples, FN mRNA and protein levels in SSc patient fibroblasts were higher than those in their healthy twins. E2 increased FN mRNA and protein levels in healthy twin and SSc fibroblasts (Figure 1A,B). E2 increased FN mRNA and protein levels in a time-dependent and dose-dependent manner in cell supernatants and ECM (Figure 1C,D). E2 induced production of total FN and EDA-domaincontaining matrix FN (Figure 1C) and the increase in secreted FN was significant (Figure 1E). The ER antagonist ICI 182,780 blocked the effect of E2 on FN mRNA and protein expression but did not affect transforming growth factor beta-induced FN levels (Figure 1F).

\section{Signaling pathways mediating the effects of $17 \beta$-estradiol} on fibronectin induction

To investigate the mechanism mediating E2 induction of FN, we pretreated skin fibroblasts with vehicle, MEK inhibitor, PI3K inhibitor, or p38 MAPK inhibitor for 1 hour 


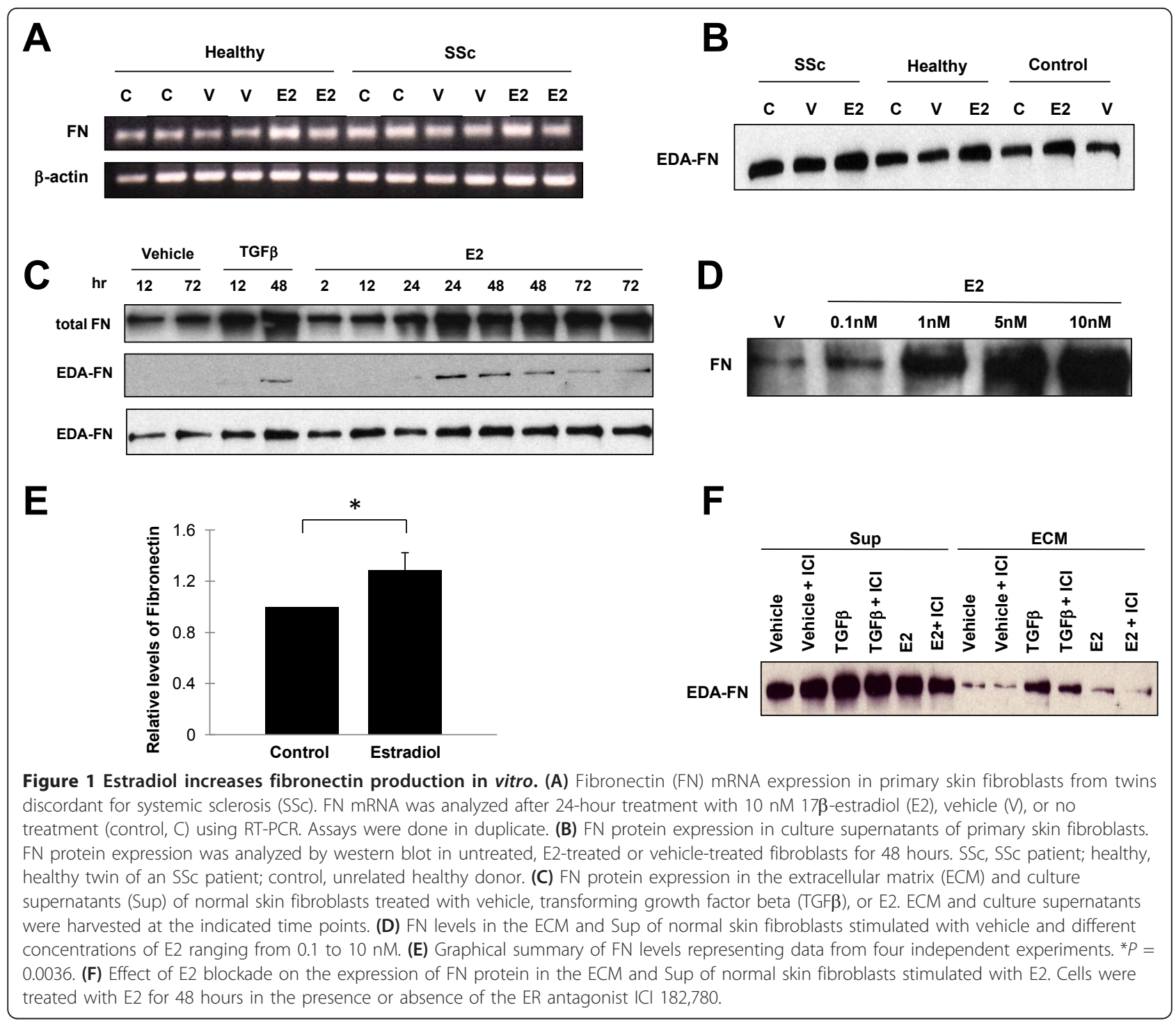

prior to the addition of E2. FN protein levels were assessed by western blot analysis 48 hours post treatment. PI3K inhibitor and p38 MAPK inhibitor attenuated the E2-mediated increase of FN (Figure 2A). MEK inhibitor had a more modest effect on E2 induction of FN. We also examined the effect of the chemical inhibitors on ER $\alpha$ and ER $\beta$. ER $\alpha$ was increased by E2 and this increase was blocked by PI3K inhibitor, p38 MAPK inhibitor, and MEK inhibitor. There was no significant difference in the expression of ER $\beta$ under the same conditions (Figure 2A).

\section{Effect of ER ligands on fibronectin expression}

To assess the individual effects of ER $\alpha$ and/or ER $\beta$ on FN expression, we used PPT, an ER $\alpha$ ligand, and genistein, an ER $\beta$ ligand. Primary fibroblasts were treated with vehicle, E2, PPT, or genistein for 48 hours. ECM was harvested and analyzed by western blot. Vitronectin was detected as an ECM loading control. E2 and PPT increased FN protein levels in the ECM (Figure 2B). Genistein modestly increased FN protein levels (Figure 2B). Vitronectin levels were not altered by any of the treatments.

Estradiol and ER $\alpha$ agonist induce increased dermal and collagen bundle thickening and fibronectin deposition in human skin

To further examine the effect of E2 in skin tissues, the dermal and collagen bundle thicknesses in dermis were assessed using an ex vivo organ culture system. Explanted skin tissues on $35 \mathrm{~mm}$ well plates were treated with E2, $\mathrm{ER} \alpha$ or ER $\beta$ agonists (PPT or genistein, respectively), or vehicle (ethanol for E2 and PPT, and dimethylsulfoxide for genistein) for 7 days, and skin sections were stained with $\mathrm{H} \& \mathrm{E}$. As shown in Figure 3, E2 and PPT induce increase of dermal thickness (Figure 3A) and collagen 


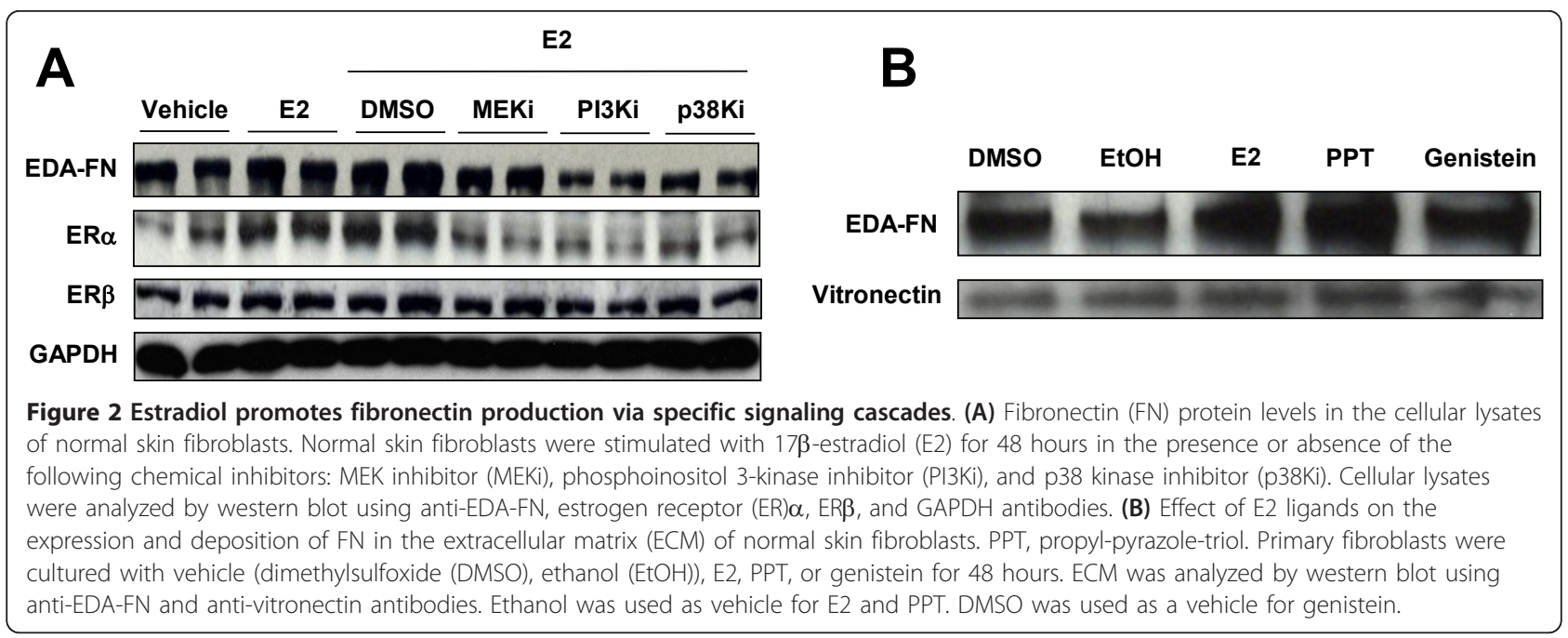

bundle thickness (Figure 3B) compared with vehicle (dermis: $1.61 \pm 0.12, P<0.05$ and $1.54 \pm 0.05, P<0.05$, respectively; collagen bundles: $2.62 \pm 0.18, P<0.05$ and $1.84 \pm$ $0.15, P<0.05$, respectively), and ICI 182,780 blocked the effect of E2. On the contrary, genistein did not induce thickening of dermis or collagen bundles (Figure 4A,B). We also assessed the extent of deposition of FN using immunohistochemistry. As shown in Figure 4, the results of FN deposition in collagen bundles were similar to those for thickness of skin and collagen bundles. E2 thus induces skin fibrosis, and this effect is mediated by ER $\alpha$.

\section{Circulating levels of $17 \beta$-estradiol and estrone are significantly increased in postmenopausal patients with systemic sclerosis}

Patient and control E2 serum samples were divided into low $(<5 \mathrm{pg} / \mathrm{ml})$, intermediate ( 5 to $10 \mathrm{pg} / \mathrm{ml}$ ), and high $(>10 \mathrm{pg} / \mathrm{ml}$ ) levels (Table 1). Similarly, patient and control estrone serum samples were divided into low $(<15 \mathrm{pg} / \mathrm{ml})$, intermediate (15 to $75 \mathrm{pg} / \mathrm{ml})$, and high $(>75 \mathrm{pg} / \mathrm{ml}$ ) levels (Table 1). There was a significant difference between SSc patient and control E2 and estrone levels $(P=0.04$ and $P=0.006$, respectively). The frequency of the data points is shown in the dot plots of Figure 5. Levels of E2 and estrone were also analyzed by disease specific clinical manifestations occurring at any time during the illness. Although the associations did not reach statistical significance, a larger proportion of patients with high estrone levels (42\%) had gastrointestinal involvement compared with those patients with low estrone levels $(17 \%, P=0.07)$.

\section{Discussion}

We present data establishing a role for E2 in the induction of a fibrotic phenotype. E2 was previously demonstrated to increase collagen during wound healing $[16,17]$. We and others have previously reported that FN mRNA levels in SSc dermal fibroblasts are up to 10-fold greater than those in healthy donors $[18,19]$. E2 increases FN mRNA in cardiac fibroblasts and this increase was associated with ECM remodeling [20]. However, the mechanism(s) mediating the effect of E2 on FN expression are poorly understood. To our knowledge, this report is the first to delineate the mechanisms mediating E2 induction of FN in human skin.

SSc is more frequent in women than men and the female:male ratio further increases to 10:1 during the child-bearing years $[1,3]$. E2 levels in women during the child-bearing years are significantly higher than those in postmenopausal women. The menstrual cycle has four phases (menstrual, follicular, ovulatory, and luteal), and each phase is characterized by different circulating levels of E2 [21]. These E2 levels during ovulation are 490 to $1,710 \mathrm{pmol} / \mathrm{l}$ (mean 1,087 pmol/l) and exceed levels detected during the other phases [22]. E2 levels in postmenopausal women are 2 to $18 \mathrm{pg} / \mathrm{ml}$ (mean $7.6 \mathrm{pg} / \mathrm{ml}$ ) [23], which is equivalent to $28 \mathrm{pmol} / \mathrm{l}$ and significantly lower than levels in women of child-bearing age. Circulating E2 levels are thus increased in the age range during which the SSc female:male ratio is highest. E2 levels that promoted a fibrotic phenotype in our assays were physiological and ranged from 0.1 to $10 \mathrm{nM}$. These levels were similar to levels measured in the circulation of women during ovulation (average $1 \mathrm{nM}$ ) [22].

Our data confirm the expression of ER $\alpha$ and ER $\beta$ in primary dermal fibroblasts [24]. We further show that PPT, an ER $\alpha$ specific ligand, increases FN production. Moreover, $\mathrm{ER} \alpha$ is increased by E2 treatment of skin fibroblasts. These results suggest that ER $\alpha$ is the main regulator of E2mediated FN expression in dermal fibroblasts. Interestingly, ER $\beta$ levels were much lower in SSc patient fibroblasts than in healthy twin fibroblasts (data not shown). ER $\beta$ expression is decreased in colon and prostate cancers and its 

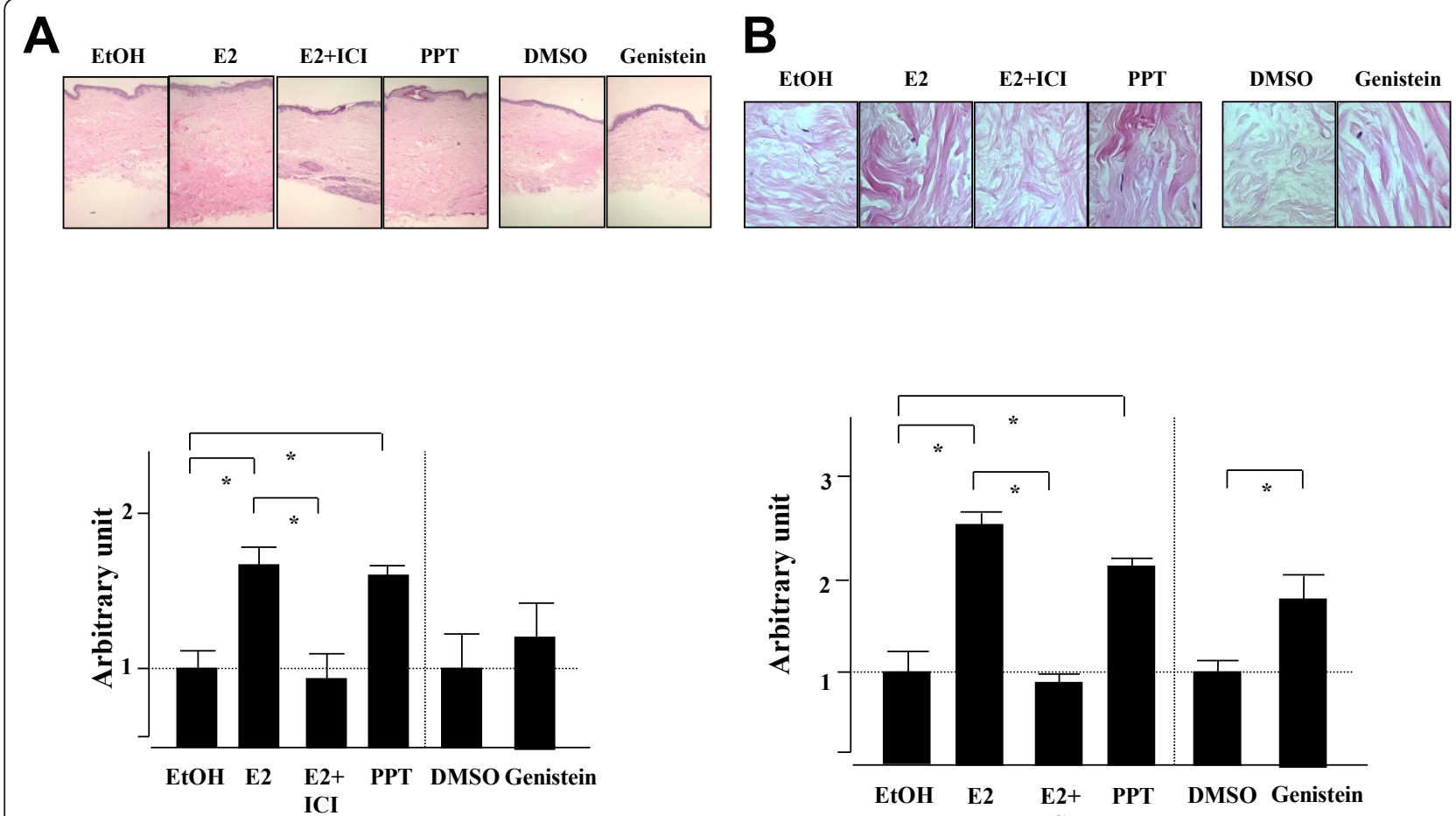

Figure 3 Estradiol promotes the development of fibrosis ex vivo in human skin. (A) Estrogen and estrogen receptor (ER $\alpha$ ) agonist induce skin thickening ex vivo. Human skin samples were plated on six-well plates and treated with ethanol (EtOH), 17ß-estradiol (E2), estradiol with ICI 182,780 (E2+|CI), propyl-pyrazole-triol (PPT), dimethylsulfoxide (DMSO), and genistein for 7 days. (A) Images of H \& E-stained sections taken at 40X magnification. Skin thickness was measured and the ratio of the thickness compared with vehicle control (EtOH or DMSO) was calculated as an arbitrary unit. Data shown are from three independent experiments. ${ }^{*} P>0.05$ by Mann-Whitney $U$ test. (B) Estrogen and ER $\alpha$ agonist also induce collagen bundle thickening in ex vivo. Human skin samples were treated with EtOH, E2, E2+ICl, PPT, DMSO, or genistein for 7 days. Images of $\mathrm{H} \&$ E-stained sections are shown. Images taken at 800x magnification. Thickness of collagen bundles was measured and the ratio compared with vehicle control (EtOH or DMSO) was calculated as an arbitrary unit. Data shown are from three independent experiments. ${ }^{*} P$ $>0.05$ by Mann-Whitney $U$ test.

reduced expression is related to tumor cell dedifferentiation [25-30]. Global antagonism of ER $\alpha$ transcriptional activity by ER $\beta$ has been reported [31]. ER $\beta$ represses several ER $\alpha$-mediated effects, including fat reduction and cellular proliferation in the uterus and prostate [31]. We further show that E2, acting via $E R \alpha$, exerts profibrotic effects. The FN-promoting effects of E2 were confirmed in vitro in dermal fibroblasts during the preparation of this manuscript by Soldano and colleagues [32]. These effects are probably tissue specific, however, since E2 attenuates tubulointerstitial fibrosis in diabetic nephropathy [33]. In summary, our findings suggest that ER $\beta$ could play a protective role in SSc. A similar antifibrotic role for $\operatorname{ER} \beta$ was recently reported in a model of cardiac fibrosis [34]. Further studies are needed to determine whether ER $\alpha$ and ER $\beta$ can exert converter-regulatory effects in the modulation of FN expression in SSc and normal dermal fibroblasts.

ER acts as a ligand-activated transcription factor. The classical mechanism of ER action involves estrogen binding to nuclear receptors followed by receptor dimerization and binding to specific response elements known as estrogen response elements located in the promoters of target genes. Dimerized receptors can also bind other transcription factors such as AP-1 and SP-1 [35-37]. Estrogens exert some of their effects through the action of ERs on gene expression, but a number of other effects of estrogens are so rapid that they cannot rely on the activation of RNA or protein synthesis. These actions are known as nongenomic actions and are believed to be mediated through membrane-associated ERs. Most endogenous plasma membrane ERs exist as homodimers in the presence of E2 [38] and mediate rapid E2 activation of a number of signaling cascades, including cyclic AMP, PI3K, phospholipase C, and MAPK [39]. These signaling pathways regulate cytokine production, apoptosis, cell cycle arrest, regulation of RNA splicing or stabilization, and tumor cell differentiation [40,41].

The MAPK superfamily consists of three well-characterized subfamilies [42]. Extracellular signal-regulated kinases respond to growth factors or other external mitogenic signals and are involved in promoting cell proliferation. The 


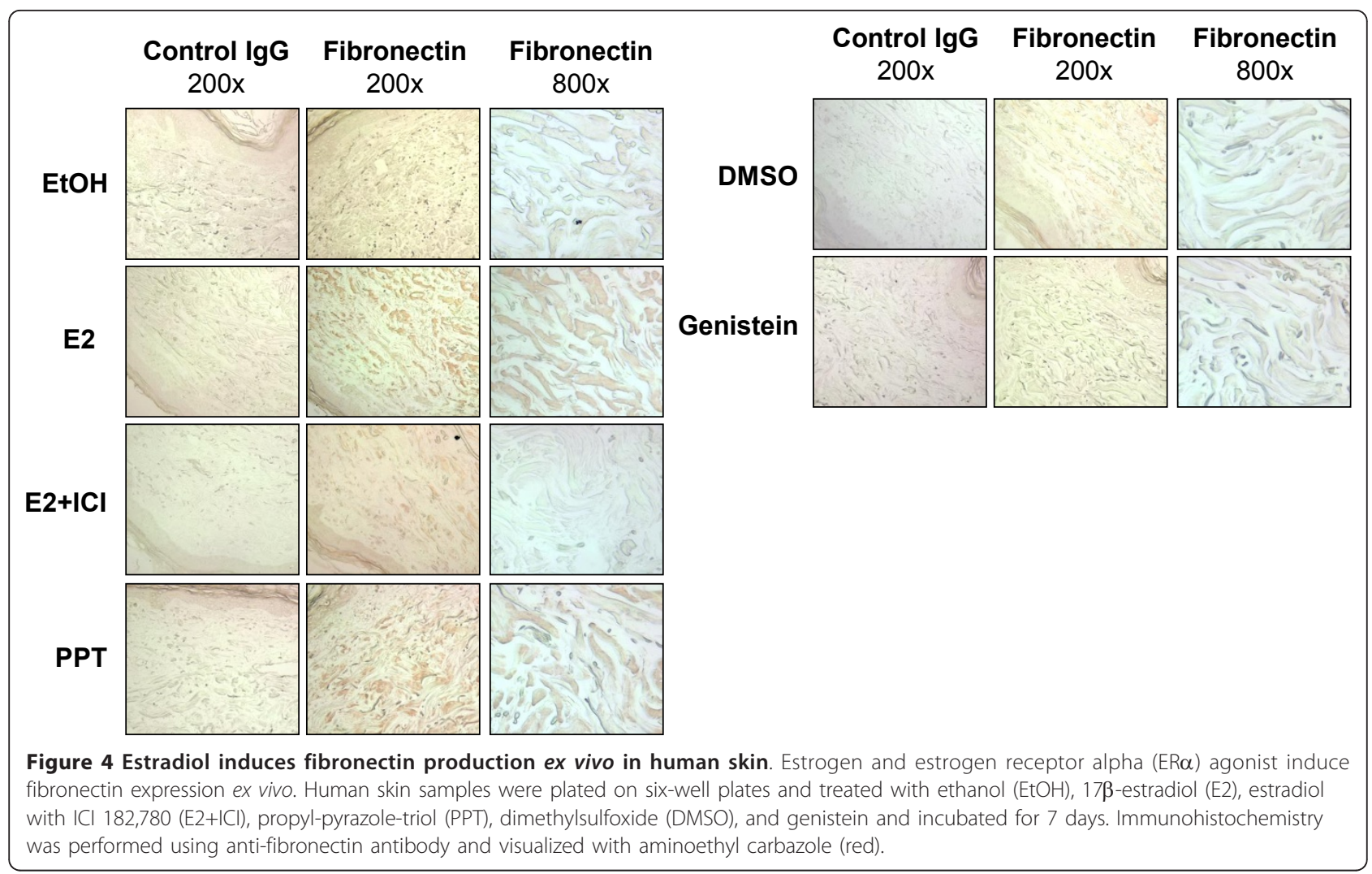

p38 MAPK and c-Jun N-terminal kinase pathways are distinguished by generally being activated in response to stress and are thus called the stress-activated kinases that promote inflammation and programmed cell death [43]. PI3K also has an important role in mitosis, apoptosis, motility, proliferation, and differentiation [44]. We have demonstrated that all three kinases (extracellular signalregulated kinase MAPK, p38K MAPK and PI3K) regulate E2 signaling and its induction of FN expression, with FN induction being mainly regulated by PI3K and p38 MAPK

Table 1 Levels of estradiol and estrone in patients with diffuse cutaneous systemic sclerosis and healthy controls

\begin{tabular}{ccccc}
\hline & Low & Intermediate & High & Total \\
\hline Estradiol $^{\mathrm{a}}$ & & & & \\
Controls & 14 & 20 & 1 & 35 \\
dcSSc & 34 & 24 & 10 & 68 \\
Total & 48 & 44 & 11 & 103 \\
Estrone $^{\mathrm{b}}$ & & & & \\
Controls & 7 & 18 & 0 & 25 \\
dcSSc & 9 & 31 & 15 & 55 \\
Total & 16 & 49 & 15 & 80
\end{tabular}

${ }^{\mathrm{a}} \operatorname{Low}(<5 \mathrm{pg} / \mathrm{ml})$, intermediate $(5$ to $10 \mathrm{pg} / \mathrm{ml})$, and high $(>10 \mathrm{pg} / \mathrm{ml}) ; P=0.04$ for controls versus diffuse cutaneous systemic sclerosis (dcSSc) using chisquare/Fisher's exact test. ${ }^{b}$ Low $(<15 \mathrm{pg} / \mathrm{ml})$, intermediate (15 to $\left.75 \mathrm{pg} / \mathrm{ml}\right)$, and high $(>75 \mathrm{pg} / \mathrm{ml}) ; P=0.006$ for controls versus dcSSc using chi-square/ Fisher's exact test. and to a lesser extent by extracellular signal-regulated kinase MAPK. PI3K and p38 MAPKs have also been reported to regulate E2/ER's anti-apoptotic action on cardiomyocytes [41]. Our findings support the role of these E2 signaling cascades in skin fibroblasts and in the regulation of ECM production.

We had previously shown that human skin maintained in an organ culture system can be used to recapitulate in vivo events and to test the efficacy of antifibrotic agents [13]. Our current data demonstrate that E2 can exert profibrotic activity ex vivo in human skin and that this effect can be specifically blocked by ICI 182,780 . The extension of our data describing the profibrotic effects of E2 to human tissues supports the applicability of our findings to human disease and the potential therapeutic effects of ICI 182,780 for human fibrosis.

The preponderance of SSc in women suggests that estrogens play a role in disease pathogenesis. We show that circulating E2 and estrone levels are elevated in postmenopausal patients with diffuse cutaneous SSc compared with healthy women, implicating estrogens, and specifically E2 and estrone, in the disease process. Numerous studies have shown that dermal skin thickness and collagen content increase in women on estrogen replacement therapy $[45,46]$. Furthermore, clinical trials have shown that postmenopausal women on HRT have thicker skin compared with women not taking HRT 


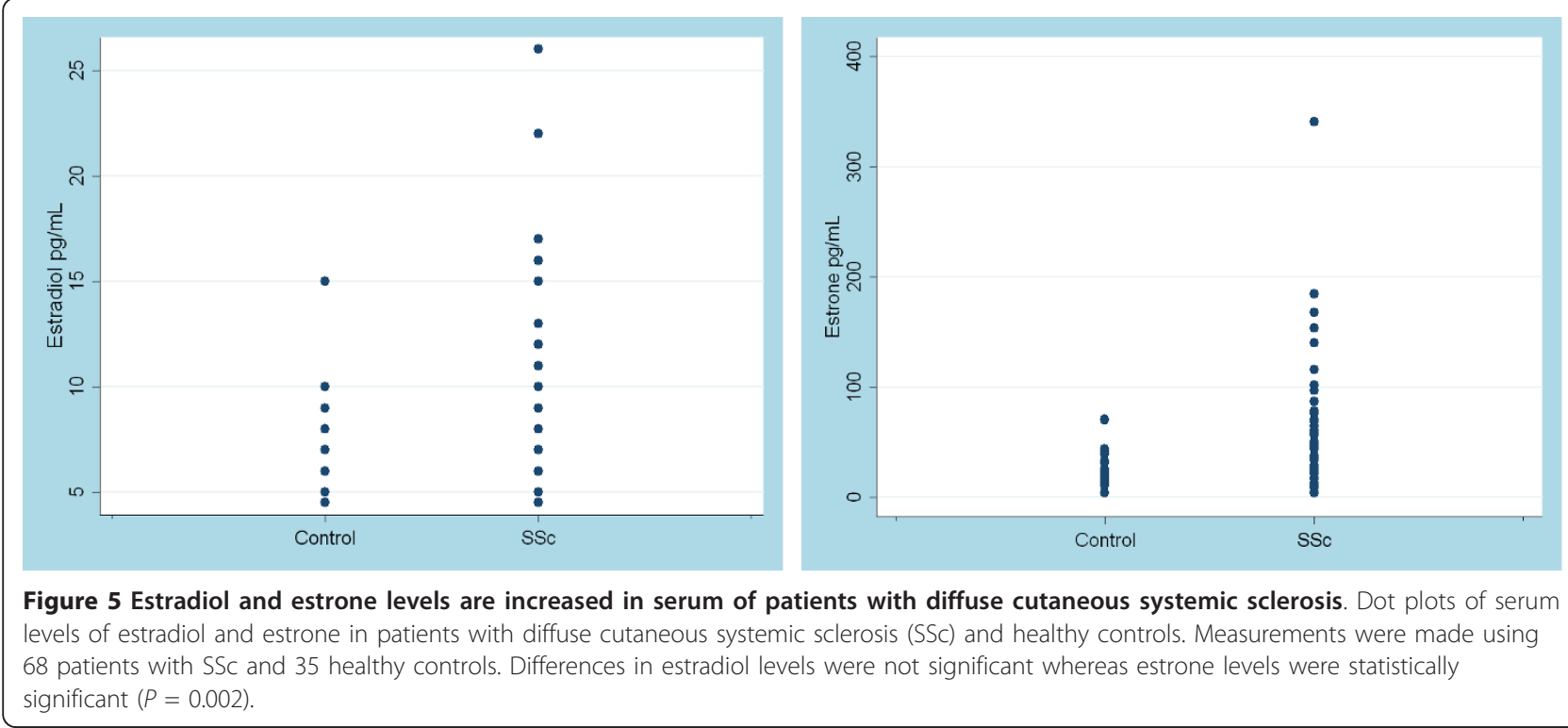

[47-50]. The profibrotic role of E2 has been confirmed in the bleomycin-induced rat lung fibrosis model where female animals had a more profound fibrotic response compared with males, which was attenuated following ovariectomy and accentuated with HRT [51]. In mice, castration decreases skin thickness and ovariectomy reduces expression of matrix-associated proteoglycans [52], suggesting that the absence of sex steroid hormones reduces expression of ECM components. These reports further support the role of estrogens in the development of fibrosis in SSc and suggest that E2 can be a trigger of ECM production and fibrosis.

Estrogen has been implicated in autoimmune diseases based on its ability to promote B-lymphocyte survival and activation, thus facilitating autoreactivity [53]. In the setting of inflammation, accelerated conversion of androgens to estrogen metabolites via aromatase occurs in the peripheral tissues [53]. This peripheral conversion may contribute to increased E2 levels in postmenopausal patients with SSc. Concentrations of E2 in skin from individuals with SSc probably exceed those detected in the circulation due to local hormone production mediated by aromatase [53]. Our ex vivo human skin model mimics the effect of peripheral estrogens found in postmenopausal women with SSc. In autoimmunity, conversion is accelerated by the induction of aromatase activity by inflammatory cytokines such as IL-6, which is increased in autoimmune diseases including SSc $[54,55]$.

\section{Conclusion}

We have identified E2 as an inducer of FN expression in skin fibroblasts obtained from SSc patients and healthy donors. The effects of E2 on FN were mainly regulated via $\mathrm{ER} \alpha$ and the E2/ER downstream signaling cascades, PI3K and p38 MAPK. We also demonstrated that E2 is fibrotic ex vivo and that ICI 182,780 can be used effectively to inhibit dermal fibrosis. The profibrotic effect of $\mathrm{E} 2$ and the increased circulating levels of E2 and estrone may explain, at least in part, the higher frequency of SSc in women.

\section{Abbreviations}

bp: base pairs; DMEM: Dulbecco's modified Eagle's medium; E2: 17ßestradiol; ECM: extracellular matrix; ER: estrogen receptor; FN: fibronectin; H \& E: hematoxylin and eosin; HRT: hormone replacement therapy; LL: interleukin; MAPK: mitogen-activated protein kinase; PBS: phosphate-buffered saline; PCR: polymerase chain reaction; PI3K: inositol-1,4,5-triphosphate; PPT: propylpyrazole-triol; RT: reverse transcriptase; SSc: systemic sclerosis.

\section{Authors' contributions}

$\mathrm{KA}-\mathrm{Y}, \mathrm{CP}, \mathrm{HY}, \mathrm{KT}, \mathrm{PH}$, and CAF-B contributed to the in vitro assays. $\mathrm{CP}, \mathrm{JAC}$, TAM, and CAF-B contributed to the serum analysis studies. KA-Y, HY, and CAF-B contributed to the ex vivo human skin studies. All authors contributed to drafting and editing of the manuscript. All authors read and approved the manuscript for publication.

\section{Competing interests}

The authors declare that they have no competing interests.

\section{Acknowledgements}

The authors would like to thank the University of Pittsburgh Small Biomolecule Core Facility and Dr Sam Poloyac for analysis of serum estrogen levels using mass spectrometry. This study was supported by National Institutes of Health AR050840, UL1 RR024153, AR35582, and T32Al09443.

\section{Author details}

'Division of Pulmonary, Allergy, and Critical Care Medicine, Department of Medicine, University of Pittsburgh School of Medicine, 3459 Fifth Avenue, 628 NW MUH, Pittsburgh, PA 14213, USA. ${ }^{2}$ Division of Rheumatology and Clinical Immunology, Department of Medicine, University of Pittsburgh School of Medicine, BST South $7^{\text {th }}$ floor, Pittsburgh, PA 15261, USA. ${ }^{3}$ Department of Pharmacology and Therapeutics, Roswell Park Cancer Institute, Elm \& Carlton Streets, Buffalo, NY 14263, USA. ${ }^{4}$ Department of 
Epidemiology, University of Pittsburgh Graduate School of Public Health, A510 Crabtree Hall, Pittsburgh, PA 15261, USA.

Received: 25 September 2012 Revised: 10 December 2012

Accepted: 21 December 2012 Published: 10 January 2013

\section{References}

1. Silver RM, Medsger TA Jr, Bolster MB: Systemic sclerosis and scleroderma variants: clinical aspects. In Arthritis and Allied Conditions. Edited by: Koopman WJ, Moreland LW. Philadelphia, PA: Lippincott, Williams 2005:1633-1680.

2. Highland KB, Silver RM: New developments in scleroderma interstitial lung disease. Curr Opin Rheumatol 2005, 17:734-745.

3. Deroo BJ, Korach KS: Estrogen receptors and human disease. J Clin Invest 2006, 116:561-570

4. Henderson BE, Feigelson HS: Hormonal carcinogenesis. Carcinogenesis 2000, 21:427-433.

5. Harris HA, Albert LM, Leathurby Y, Malamas MS, Mewshaw RE, Miller CP, Kharode YP, Marzolf J, Komm BS, Winneker RC, Frail DE, Henderson RA, Zhu Y, Keith JC Jr: Evaluation of an estrogen receptor-beta agonist in animal models of human disease. Endocrinology 2003, 144:4241-4249.

6. Wise PM, Dubal DB, Wilson ME, Rau SW, Bottner M: Minireview. Neuroprotective effects of estrogen: new insights into mechanisms of action. Endocrinology 2001, 142:969-973.

7. Hurn PD, Sacco RL: Sex, steroids and stroke: introduction. Stroke 2004, $35: 2642-2643$

8. Ohlsson C, Hellberg N, Parini P, Vidal O, Bohlooly-Y M, Rudling M, Lindberg MK, Warner M, Angelin B, Gustafsson JA: Obesity and disturbed lipoprotein profile in estrogen receptor-alpha-deficient male mice. Biochem Biophys Res Commun 2006, 278:640-645.

9. Beretta L, Caronni M, Origgi L, Ponti A, Santaniello A, Scorza R: Hormone replacement therapy may prevent the development of isolated pulmonary hypertension in patients with systemic sclerosis. Scand I Rheumatol 2006, 35:468-471.

10. Thomas-Golbanov CK, Wilke WS, Fessler BJ, Hoffman GS: Open label trial of tamoxifen in scleroderma. Clin Exp Rheumatol 2003, 21:99-102.

11. Feghali-Bostwick C, Medsger TA Jr, Wright TM: Analysis of systemic sclerosis in twins reveals low concordance for disease and high concordance for the presence of antinuclear antibodies. Arthritis Rheum 2003, 48:1956-1963.

12. Zhou X, Tan FK, Xiong M, Arnett FC, Feghali-Bostwick CA: Monozygotic twins clinically discordant for scleroderma show concordance for fibroblast gene expression profiles. Arthritis Rheum 2005, 52:3305-3314

13. Sun J, Meyers MJ, Fink BE, Rajendran R, Katzenellenbogen JA, Katzenellenbogen BS: Novel ligands that function as selective estrogens or antiestrogens for estrogen receptor-alpha or estrogen receptor-beta. Endocrinology 1999, 140:800-804.

14. Pilewski JM, Liu L, Henry AC, Knauer AV, Feghali-Bostwick CA: Insulin-like growth factor binding protein 3 and 5 are overexpressed in idiopathic pulmonary fibrosis and contribute to extracellular matrix deposition. Am J Pathol 2005, 166:399-407.

15. Yasuoka H, Larregina AT, Yamaguchi Y, Feghali-Bostwick CA: Human skin culture as an ex vivo model for assessing the fibrotic effects of insulinlike growth factor binding proteins. Open Rheumatol J 2008, 2:17-22.

16. Ashcroft GS, Dodsworth J, van Boxtel E, Tarnuzzer RW, Horan MA, Schultz GS, Ferguson MW: Estrogen accelerates cutaneous wound healing associated with an increase in TGF- $\beta 1$ levels. Nat Med 1997, 3:1209-1215.

17. Ashcroft GS, Greenwell-wild T, Horan MA, Wahl SM, Ferguson MW: Topical estrogen accelerates cutaneous wound healing in aged humans associated with an altered inflammation response. Am J Pathol 1999, 155:1137-1146.

18. Feghali CA, Wright TM: Identification of multiple, deferentially expressed messenger RNAs in dermal fibroblasts from patients with systemic sclerosis. Arthritis Rheum 1999, 42:1451-1457.

19. Meyringer R, Neumann E, Judex M, Landthaler M, Kullmann F, Scholmerich J, Gay S, Tarner IH, Distler O, Müller-Ladner U: Analysis of gene expression patterns in systemic sclerosis fibroblasts using RNA arbitrarily primed-polymerase chain reaction for different display. I Rheumatol 2007, 34:747-753.

20. Mercier I, Colombo F, Mader S, Calderone A: Ovarian hormones induce TGF-beta (3) and fibronectin mRNAs but exhibit a disparate action on cardiac fibroblast proliferation. Cardiovasc Res 2002, 53:728-739.
21. Ziegler WF, Bernstein I, Badger G, Leavitt T, Cerrero ML: Regional hemodinamic adaptation during the menstrual cycle. Obstet Gynecol 1999, 94:695-699.

22. Bakos O, Lundkvist $\mathrm{O}$, Wide L, Bergh T: Ultrasonographical and hormonal description of normal ovulatory menstrual cycle. Acta Obstet Gynecol Scand 1994, 73:790-796.

23. Notelovitz M, Funk S, Nanavati N, Mazzeo M: Estradiol absorption from vaginal tablets in postmenoposal women. Obstet Gynecol 2002, 99:556-562.

24. Haczynski J, Tarkowski R, Jarzabek K, Slomczynska M, Wolczynski S, Magoffin DA, Jakowicki JA, Jakimiuk AJ: Human cultured skin fibroblasts express estrogen receptor alpha and beta. Int J Mol Med 2002, 10:149-153.

25. Foley EF, Jazaeri AA, Shupnik MA, Jazaeri O, Rice LW: Selective loss of estrogen receptor beta in malignant human colon. Cancer Res 2000, 60:245-248.

26. Jassam N, Bell SM, Speirs V, Quirke P: Loss of expression of oestrogen receptor beta in col on cancer and its association with Duke's staging. Oncol Rep 2005, 14:17-21.

27. Konstantinopoulos PA, Kominea A, Vandoros G, Sykiotis GP, Andricopoulos P, Varakis I, Sotiropoulou-Bonikou G, Papavassiliou AG: Oestrogen receptor beta (ER $\beta$ ) is abundantly expressed in normal colonic mucosa, but declines in colon adenocarcinoma paralleling the tumor's dedifferentiation. Eur J Cancer 2003, 39:1251-1258

28. Campbell-Thompson M, Lynch IJ, Bhardwaj B: Expression of estrogen receptor (ER) subtypes and ER $\beta$ isoforms in colon cancer. Cancer Res 2001, 61:632-640.

29. Leav I, Lau KM, Adams JY, McNeal JE, Taplin ME, Wang J, Singh H, Ho SM: Comparative studies of the estrogen receptors beta and alpha and the androgen receptor in normal human prostate glands, dysplasia, and in primary and metastatic carcinoma. Am J Pathol 2001, 159:79-92.

30. Horvath LG, Henshall SM, Lee CS, Head DR, Quinn DI, Makela S, Delprado W, Golovsky D, Brenner PC, O'Neill G, Kooner R, Stricker PD, Grygiel JJ, Gustafsson JA, Sutherland RL: Frequent loss of estrogen receptor-beta expression in prostate cancer. Cancer Res 2001, 61:5331-5335.

31. Weihua Z, Makela S, Andersson LC, Salmi S, Saji S, Webster Jl, Jensen EV, Nilsson $S$, Warner M, Gustafsson JA: A role for estrogen receptor $\beta$ in the regulation of growth of the ventral prostate. Proc Natl Acad Sci USA 2001, 98:6330-6335.

32. Soldano S, Montagna P, Brizzolara R, Sulli A, Parodi A, Seriolo B, Paolino S, Villaggio $B$, Cutolo M: Effects of estrogens on extracellular matrix synthesis in cultures of human and normal scleroderma skin fibroblasts. Ann N Y Acad Sci 2010, 1193:25-29.

33. Mankhey RW, Wells CC, Bhatti F, Maric C: $17 \beta$-estradiol supplementation reduces tubulointerstitial fibrosis by increasing MMP activity in the diabetic kidney. Am J Physiol Regul Integr Comp Physiol 2007, 292: R769-R777.

34. Pedram A, Razandi M, O'Mahony F, Lubahn D, Levin ER: Estrogen receptorbeta prevents cardiac fibrosis. Mol Endocrinol 2010, 24:2152-2165.

35. Nilsson S, Mäkelä S, Treuter E, Tujague M, Thomsen J, Andersson G, Enmark E, Pettersson K, Warner M, Gustafsson JA: Mechanisms of estrogen action. Physiol Rev 2001, 81:1535-1565.

36. O'Lone R, Frith MC, Karlsson EK, Hansen U: Genomic targets of nuclear estrogen receptors. Mol Endocrinol 2004, 18:1859-1875.

37. Gottlicher M, Heck S, Herrlich P: Transcriptional cross-talk, the second mode of steroid hormone receptor action. J Mol Med 1998, 76:480-489.

38. Razandi M, Pedram A, Merchenthaler I, Greene GL, Levin ER: Plasma membrane estrogen receptors exist and functions as dimers. Mol Endocrinol 2004, 18:2854-2865.

39. Levin ER: Cellular functions of plasma membrane estrogen receptors. Steroid 2002, 67:471-475.

40. Olson JM, Hallahan AR: P38 MAP kinase: a convergence point in cancer therapy. Trends Mol Med 2004, 10:125-129.

41. Kim JK, Levin ER: Estrogen signaling in the cardiovascular system. NuCl Res Signaling 2006, 4:1-5.

42. Chang L, Karin M: Mammalian MAP kinase signaling cascades. Nature 2001, 410:37-40

43. Xia Z, Dickens M, Raingeaud J, Davis RJ: Opposing effects of ERK and JNKp38 kinases in apoptosis. Science 1995, 270:1326-1331.

44. Redaelli C, Granucci F, De Gioia L, Cipolla L: Synthesis and biological activity of Akt/PI3K inhibitors. Mini Rev Med Chem 2006, 6:1127-1136. 
45. Brincat M, Moniz CJ, Studd JW, Darby A, Magos A, Emburey G, Versi E: Long-term effects of the menopause and sex hormones on skin thickness. Br J Obstet Gynaecol 1985, 92:256-259.

46. Meschia M, Bruschi F, Amicarelli F, Barbacini P, Monza GC, Crosignani PG: Transdermal hormone replacement therapy and skin in postmenopausal women, a placebo controlled study. Menopause 1994, 1:79-82.

47. Maheux R, Naud F, Rioux M, Grenier R, Lemay A, Guy J, Langevin M: A randomized, double-blind, placebo-controlled study on the effect of conjugated estrogens on skin thickness. Am J Obstet Gynecol 1994, 170:642-649

48. Castelo-Branco C, Duran M, Gonzalez-Merlo J: Skin collagen changes related to age and hormone replacement therapy. Maturitas 1992, 15:113-119.

49. Kalogirou D, Aroni K, Kalogirou O, Antoniou G, Botsis D, Kontoravdis A: Histological changes induced by tibolone and estrogen/glucocorticoid on aging skin. Int J Fertil Womens Med 2000, 45:273-278.

50. Hall G, Phillips TJ: Estrogen and skin: the effects of estrogen, menopause, and hormone replacement therapy on the skin. J Am Acad Dermatol 2005, 53:555-568.

51. Charaee-Kermani M, Hatano K, Nozaki Y, Phan SH: Gender-based differences in bleomycin-induced pulmonary fibrosis. Am J Pathol 2005, 166:1593-1606.

52. Markiewicz M, Asano Y, Znoyko S, Gong Y, Watson DK, Trojanowska M: Distinct effects of gonadectomy in male and female mice on collagen fibrillogenesis in the skin. J Dermatol Sci 2007, 47:217-226.

53. Inoue T, Miki Y, Abe K, Hatori M, Hosaka M, Kariya Y, Kakuo S, Fujimura T, Hachiya A, Honma S, Aiba S, Sasano H: Sex steroid synthesis in human skin in situ: the role of aromatase and steroidogenic acute regulatory protein in the homeostasis of human skin. Mol Cell Endocrinol 2012, 362:19-28.

54. Cutolo M, Sulli A, Straub RH: Estrogen metabolism and autoimmunity. Autoimmun Rev 2012, 11:A460-A464.

55. Feghali CA, Bost KL, Boulware DW, Levy LS: Mechanisms of pathogenesis in scleroderma. I. Overproduction of interleukin 6 by fibroblasts cultured from affected skin sites of patients with scleroderma. J Rheumatol 1992, 19:1207-1211.

doi:10.1186/ar4140

Cite this article as: Aida-Yasuoka et al:: Estradiol promotes the development of a fibrotic phenotype and is increased in the serum of patients with systemic sclerosis. Arthritis Research \& Therapy 2013 15:R10

\section{Submit your next manuscript to BioMed Central and take full advantage of:}

- Convenient online submission

- Thorough peer review

- No space constraints or color figure charges

- Immediate publication on acceptance

- Inclusion in PubMed, CAS, Scopus and Google Scholar

- Research which is freely available for redistribution

Submit your manuscript at www.biomedcentral.com/submit 